\title{
DA UTOPIA FOURIERISTA AOS PRINCÍPIOS DE ECONOMIA SOLIDÁRIA: INTERFACES ENTRE O PASSADO E O PRESENTE
}

\section{C. S. ROCHA'; G. E. F. ARAÚJO ${ }^{2}$; E. A. PELOGIO 3 ; J. A. PAIVA ${ }^{4}$; M. E. M. AÑEZ ${ }^{5}$}

${ }^{1}$ Instituto Federal do Sul de Minas Gerais - Campus Machado, ${ }^{2}$ Empresa Brasileira de Correios e Telégrafos, ${ }^{3}$ Fundação Machadense de Ensino Superior e Comunicação, ${ }^{4,5}$ Universidade Federal do Rio Grande do Norte luiz.rocha@mch.ifsuldeminas.edu.br; ge_eliakim@hotmail.com; manu-pelagio@bol.com.br; juarez.paiva@ig.com.br; anez1957@yahoo.com.br

Artigo submetido em julho/2012 e aceito em abril/2013

\section{RESUMO}

A partir de pesquisa bibliográfica, este texto evidencia, teoricamente, por vias fenomenológicas e ontológicas, como as idéias principais do Socialismo Utópico de Fourier estão presentes nos princípios da Economia Solidária. A situação sócio-econômica da sociedade contemporânea, centrada no consumismo e na competitividade, tem gerado restrições, tanto para a economia capitalista quanto para a maioria dos indivíduos. É, pois, em tempos de crise, que a Economia Solidária aparece como resposta às desigualdades e injustiças inerentes ao sistema capitalista, pois, privilegia, além da dimensão econômica, as esferas social e ambiental. Esta tendência não fragmentada de vida foi pensada no passado e vem ocorrendo - ainda que de modo limitado - nos dias atuais. Para evidenciar tal entendimento, ao longo do trabalho são resgatadas características do pensamento de Fourier que, hoje, aparecem fortemente vinculadas ao construto da Economia Solidária. O exercício procedido evidencia a vitalidade dos ideais do socialismo utópico na atualidade.

PALAVRAS-CHAVE: Fourier, Economia Solidária, Capitalismo.

\section{FROM UTOPIA TO PRINCIPLES OF SOLIDARITY ECONOMY: INTERFACES BETWEEN THE PAST AND THE PRESENT}

\begin{abstract}
From a bibliographic research, this text shows, theoretically, by phenomenological and ontological ways, how the main ideas of Fourier's Utopian Socialism are present in principles of Solidarity Economy. The contemporary society's socioeconomic situation, based in consumerism and competitiveness, has created constraints, both for the capitalist economy and for most individuals. It is in times of crisis that Solidarity Economy appears as answer to inequalities and
\end{abstract}

injustices inherent to capitalist system, focusing beyond the economy dimension, the social and environmental spheres. This not fragmented trend of life was thought in the past and is occurring - though in a limited way nowadays. To show this understanding, throughout the work are recovered features of Fourier's thought that, today, appear strongly linked to the construct of Solidarity Economy. The realized exercise shows the vitality of the utopian socialism' ideals in the present.

KEY-WORDS: Fourier, Solidarity Economy, Capitalism. 


\section{DA UTOPIA FOURIERISTA AOS PRINCÍPIOS DE ECONOMIA SOLIDÁRIA: INTERFACES ENTRE O PASSADO E O PRESENTE}

\section{INTRODUÇÃO}

A atual situação da sociedade, onde consumismo e competitividade são palavras de ordem que guiam a atitudes, tem gerado colapsos, tanto para a economia capitalista, com suas crises periódicas, quanto para o indivíduo, que se torna ser alienado pela transformação da racionalidade num instrumento disfarçado de perpetuação da repressão social, em vez de sinônimo de razão.

Essa transgressão de valores da sociedade atual remonta à época do lluminismo, que tinha por intenção inicial promover a razão como instrumento de emancipação humana, tornando o homem consciente de sua realidade e responsável pelo seu próprio destino. Entretanto, ao se direcionar para a ciência e para a técnica, o movimento gerou um resultado perverso, transformando-se em razão instrumental e servindo de ferramenta para a manutenção de poder através da dominação. Corroborando essa afirmação, Engels (1981, p.29) cita:

\footnotetext{
já sabemos, hoje, que este império da razão não era mais do que o império idealizado pela burguesia; que a justiça eterna tomou corpo na justiça burguesa; que a igualdade se reduziu à igualdade burguesa em face da lei, que, como um dos direitos mais essenciais do homem, foi proclamada a propriedade burguesa; e que o Estado da razão, [...] foi convertido na república democrática burguesa.
}

Diante disso, os estragos sociais causados pelo capitalismo exacerbado são cada vez mais evidentes e as estratégias utilizadas para corrigir esses estragos mal conseguem minimizá-los. Ao se analisar uma estrutura social marcada pela desigualdade, as consequências sociais como o desemprego e a precarização do trabalho, passam a produzir novos e amplos contingentes de excluídos.

Neste contexto, a Economia Solidária surge como modo de produção e distribuição alternativo ao capitalismo, criado e recriado periodicamente pelos que se encontram marginalizados do mercado de trabalho. Esse modo solidário de produção e distribuição, em um primeiro momento, parece um híbrido entre o capitalismo e a pequena produção de mercadorias. Mas, na realidade, ele constitui uma síntese que supera ambos. A Economia Solidária é uma criação em processo contínuo de trabalhadores em luta contra o sistema capitalista de produção. Como tal, não poderia preceder ao capitalismo industrial, mas, acompanha-o em toda sua evolução.

As primeiras experiências de modelos de gestão diferenciadas e democráticas são frutos do pensamento cooperativista, que, ao longo da história, toma cunho de movimento social, tendo como base o Socialismo Utópico da primeira metade do século XIX, de Owen, Fourier, Saint-Simon, Buchez, Proudhon e Blanc. 
Levando em conta essas ideias iniciais o presente artigo aponta, teoricamente, por um viés fenomenológico e ontológico, e através de uma pesquisa bibliográfica, como as ideias principais do Socialismo Utópico de Fourier estão presentes nos princípios que norteiam esse expressivo movimento social, cujos principais atores são os empreendimentos econômicos solidários.

Este artigo apresenta o seguinte ordenamento: além desta primeira parte introdutória, a segunda apresenta o Socialismo Utópico de Fourier, a terceira parte aborda a Contextualização da Economia Solidária, a quarta parte traz o conceito de Economia Solidária, a quinta parte discute as Interfaces entre o Socialismo Utópico de Fourier e a Economia Solidária, a sexta parte apresenta as Considerações Finais e a última parte traz as Referências utilizadas neste trabalho.

\section{SOCIALISMO UTÓPICO DE FOURIER}

François Maria Charles Fourier (1772-1837) foi um socialista francês da primeira parte do século XIX, nasceu em Besançon, no interior da França, filho de uma rica família de comerciantes. Mas, Fourier esteve mais interessado na arquitetura que nos negócios de seu pai. De fato, queria converter-se em engenheiro, mas a Escola de Engenharia Militar aceitava somente filhos da nobreza, o que não era o seu caso. Mais tarde, Fourier se alegraria em não ter se tornado engenheiro, porque, segundo ele, esta profissão teria the consumido muito tempo afastando-o de seu verdadeiro desejo: ajudar a Humanidade. Em Julho de 1781, logo após a morte de seu pai, Fourier herda dois quintos da fortuna, avaliada em mais de 200.000 francos. Alguns anos mais tarde, com o dinheiro que havia recebido da herança do pai, tratou de fazer negócios comprando mercadorias para revendê-las. Suas operações mercantis coincidiram, contudo, com os anos agitados da Revolução Francesa, fazendo-o perder muito dinheiro e obrigando-o a voltar a trabalhar duro. O pensador francês estava convencido de que a Revolução Francesa tinha sido um equívoco, pois, partindo da percepção de que era preciso transformar a sociedade, devido ao fato de que os seres humanos estavam submetidos à pressão de instituições injustificáveis, os revolucionários acabaram por não mudar nada. Com isso, Fourier torna-se descrente em relação à luta política (tal como era praticada) e se dispõe a buscar um caminho pelo qual a transformação da sociedade poderia se viabilizar. No final do século XVIII, ele, de fato, estava empenhado em avaliar as causas da situação em que se encontrava a humanidade, que lhe parecia deplorável. Foi em 1799 que Fourier "descobriu" sua teoria, ao comer uma maçã em Paris e verificar que vinha de sua terra natal só que custando cem vezes mais do que lá. Para ele, a sua maçã teria uma importância semelhante à maçã de Newton. Então, se deu conta da "desordem fundamental do mecanismo industrial" e começou a desenvolver denúncias sistemáticas dos danos da civilização (termo que usava para designar a sociedade capitalista) à humanidade (KONDER, 1998). 
Em 1803, Fourier começou a publicar artigos e, pela primeira vez, passou a expor por escrito suas ideias. Dizia que a civilização não era o destino da humanidade e, sim, uma forma singular de organização da vida em sociedade, uma forma que estava impedindo os seres humanos de se relacionarem de modo harmônico uns com os outros e todos com a natureza. Insistiu na tese de que Deus regia o mundo, não pela coerção, mas, sim, pela "lei da atração universal". De acordo com Fourier, Deus havia organizado o mundo com base nesse princípio da atração, só que, enquanto os astros obedeciam mecanicamente aos desígnios de Deus, os homens haviam se afastado dos caminhos indicados. A civilização, então, levara ao máximo esse afastamento, gerando desordem, anarquia, especulação, parasitismo e miséria. A ideia central que move a obra de Fourier encontra-se no Princípio da Atração Universal que, segundo ele, regeria o mundo físico e social, material e espiritual (KONDER, 1998).

Para Fourier, suas teorias precisavam passar pelo teste de uma aplicação prática para demonstrarem o acerto e a seriedade do seu pensamento. A experiência da "falange experimental" ou "falanstério" (junção da palavra falange com monastério) seria decisiva. Fourier denominava falanstério o edifício onde estaria instalada a falange experimental e chegou à dimensão de 1.620 pessoas de diferentes condições sociais, porém, assegurando a presença de uma minoria de capitalistas, artistas e intelectuais. A área deveria ser próxima a uma cidade, com terra fértil, colinas, bosques e rio. A remuneração de serviços e trabalhos circularia no falanstério e ajudaria a fazer o sistema funcionar (KONDER, 1998).

Segundo esse pensador francês, os seres humanos se juntam ou se articulam de quatro formas: a amizade (predomina na infância), o amor (predomina na juventude), a ambição (predomina na maturidade), e o "familismo" (predomina na velhice). Para Fourier, por mais variadas que fossem as características das pessoas elas descobrem afinidades entre si, e, então, se aliam em torno dessas afinidades. Assim se constituiriam as "séries" que reuniriam as pessoas a partir de convergências e divergências, sendo formadas por um grupo mais influente no centro e outros grupos menos influentes à direita e à esquerda. Essas "séries" seriam as subunidades constitutivas do falanstério que valorizaria as diferenças de grupos e de indivíduos, ganhando vitalidade por força da diversidade das preferências de seus integrantes. Nenhuma concórdia poderia presumir a eliminação das discórdias, que são elementos insuprimíveis da realidade humana. Um conselho superior, composto por representantes de cada "série", cuidaria do bom funcionamento das atividades indicando as tarefas que estivessem por ser realizadas, sem jamais dar ordens ou fazer imposições. No projeto do falanstério, Fourier fundia duas aspirações: a da revalorização do espírito comunitário e a da mais completa liberdade individual para todos (KONDER, 1998).

O nome de Charles Fourier está associado a duas palavras: socialismo e utopia. A grande descoberta de Fourier, segundo ele, foi a "lei da atração passional". E, sua maior invenção, foi a do caminho a ser seguido para que, com base nessa lei, a humanidade superasse a "civilização" e fosse capaz de criar a "Harmonia" (KONDER, 1998). Como a referida invenção se inseriu no movimento histórico das ideias socialistas, Fourier foi considerado um teórico de tal concepção, 
mais tarde denominada de utópica por Marx e Engels, ao lado de outros com pensamentos similares, não revolucionários.

Mas o ponto de partida do pensamento de Fourier é uma intuição ontológica que tudo no universo está ligado a tudo. A força que move o universo e garante o equilíbrio e a magnífica sincronização nos movimentos de todos os seres é o que Fourier chama de atração passional que, para ele, devia ser reconhecida como o impulso natural anterior à reflexão, e, como intuição ontológica, precisava ser esclarecida, trabalhada pela reflexão. Para Fourier, seria absurdo abrir mão da condição de sujeito desejante para se impor à lógica da civilização. É em torno dessa ideia que o pensamento de Fourier se organiza, ou seja, em função da recusa radical à civilização e da confiança na atração passional (KONDER, 1998).

Fourier defendia, também, a liberdade das mulheres e dizia que os níveis de cultura e de progresso social em cada sociedade aconteceriam na medida em que se realizasse o avanço das mulheres em direção à liberdade. O declínio social, por sua vez, ocorreria como resultado da diminuição da liberdade delas (LEHOUCK, 1973).

Para o pensador, a evolução da humanidade percorreria os seguintes períodos em sua evolução social: $1^{\circ}$ - edênico (ou primitivo), $2^{\circ}$ - selvagem (ou de inércia), $3^{\circ}$ - patriarcal (ou de pequena indústria), $4^{\circ}$ - bárbaro (ou de média indústria) e o $5^{\circ}$ - fase da civilização (ou de grande indústria). $06^{\circ}$ período deveria ser a experiência do falanstério que permitiria o início do regime societário no $7^{\circ}$ período, o do "sociantismo", que seria a associação simples. $08^{\circ}$ período seria o da Harmonia ou da associação composta (KONDER, 1998).

Para Fourier, os civilizados temem as paixões porque elas escapam ao controle da moral. Então, desde 1806, quando escreveu "O descaminho da razão", Fourier se dedicou a analisar as "paixões radicais" dos seres humanos. Comparou-as, qualificou-as e chegou à conclusão de que elas eram doze. As cinco primeiras paixões, para ele, derivam dos órgãos dos sentidos: a paixão de olhar, a de ouvir, a do paladar, a do olfato e a do tato. Outra parte de categoria de paixões reúnem aquelas que se referem a determinados afetos, como: a paixão da amizade, a do amor, a da ambição e a do "familismo". Essas quatro paixões lidam com as relações entre as pessoas e se distinguem das cinco anteriores, que se referem às relações das pessoas com as coisas. As três últimas paixões são chamadas por Fourier de "distributivas": a compósita (da entrega do indivíduo a uma causa, um ideal), a borboleta (necessidade de ir de flor em flor sem se fixar numa coisa só) e a cabalista (leva o indivíduo a se assumir como indivíduo particular no interior de qualquer coletividade) (LEHOUCK, 1973).

Entre essas doze paixões, existe uma que, segundo Fourier, é bastante maltratada pela civilização e à qual ele dedica especial atenção: o amor. Para o filósofo, a intensidade da experiência amorosa denota uma dimensão religiosa, pois, para ele, é através do amor que o ser humano pode se elevar ao céu e partilhar a felicidade de Deus. Segundo Fourier, a paixão amorosa tem duas dimensões interdependentes, inelimináveis, que são: a do corpo e a da alma. 
Fourier destaca a importância tanto do prazer físico, da sensualidade, como a do sentimento depurado, que ele chama de "celadonismo". Na Harmonia, de acordo com o pensador francês, haveria elevada consideração pelo "celadonismo", e as pessoas desenvolveriam modos de amar mais intensos. Além disso, tanto homens quanto mulheres seriam respeitados em suas escolhas pessoais na vida amorosa, quaisquer que fossem suas opções. Desta forma, não existia, para Fourier, motivos para que o homossexualismo fosse condenado porque cada manifestação de amor expressa, ao seu modo, um impulso da atração passional. $O$ incesto igualmente seria natural em decorrência da junção de duas paixões radicais: o amor e o "familismo" (KONDER, 1998).

Além do amor, Fourier considerava importante a paixão derivada do paladar. Segundo o pensador, na Harmonia seriam oferecidas honras e recompensas materiais aos que se destacassem por virtudes amorosas, conhecimentos científicos, talentos artísticos e por realizações gastronômicas. Para Fourier, o prazer da alimentação saborosa seria o mais completo, pois, é o primeiro e o último que o ser humano experimenta; é um prazer que se desfruta desde o nascimento até a morte. Assim, o pensador propunha que a paixão manifestada pelo paladar fosse estudada por uma nova ciência: a "gastrosofia" (KONDER, 1998).

Para Fourier, no falanstério: a) as pessoas desenvolveriam hábitos mais racionais que os da civilização, porque teriam consciência das vantagens oferecidas por tais hábitos para todos e para cada um; b) a eficiência dos médicos e dentistas seria medida pelos resultados da medicina preventiva; c) a economia não eliminaria a propriedade privada e manteria o dinheiro, bem como as práticas de mercado, mas, não assumiria características vistas no mercado da civilização, porque a preservação da vida comunitária influiria nas ações dos indivíduos; d) os indivíduos iriam se sentir livres, seguros de seus desejos e de suas paixões, e, assim, teriam orgulho da organização e não teriam motivos para a competição exacerbada e destrutiva que a civilização impunha; e) a educação no falanstério seria diferente das experiências educacionais realizadas pelas sociedades civilizadas, pois, deveria ser prazerosa e composta por: artes, ópera, música, dança, teatro, mímica, poesia, pintura, enfim, todos seriam artistas. A educação das crianças seria feita, predominantemente, pelas próprias crianças: as mais velhas ensinariam às mais jovens. A intervenção dos adultos ficaria reduzida (KONDER, 1998).

Para Fourier existiriam cinco ramos do movimento universal, interligados: o "físicomecânico" que Newton estudou; o "aromal", da comunicação entre os astros; o "orgânico" das formas e das cores dos seres vivos; o "instintual" dos animais e o "passional" ou social dos seres humanos. O movimento passional coordenaria os demais e seria a chave para a compreensão dos outros. Nessas condições, a civilização, com seu sistema de repressão e desvirtuamento das paixões, deveria ser superada (KONDER, 1998).

Fourier foi, de algum modo, um dos idealizadores do cooperativismo. Sua preocupação com a defesa da autonomia das pessoas o distinguia de outros teóricos socialistas da primeira metade do século XIX. Foi também um crítico ferino do economicismo, do capitalismo de sua 
época, e adversário da industrialização, da civilização urbana, do liberalismo e da família baseada no matrimônio e na monogamia. O caráter jovial com que Fourier realizou algumas de suas críticas, fez dele um dos grandes satíricos de todos os tempos. Propôs a criação de unidades de produção e consumo, as falanges ou falanstérios baseadas em uma forma de cooperativismo integral e auto-suficiente, assim como, na livre perseguição do que chamava paixões individuais, o que construiria um estado que chamou de harmonia. Neste sentido, antecipou a linhagem do socialismo libertário dentro do movimento socialista, e, em linhas críticas da moral burguesa e cristã restritiva do desejo e do prazer, tornou-se um dos precursores do anarquismo e da psicanálise. Em 1808, Fourier defendeu abertamente a igualdade de gênero entre homens e mulheres, apesar da palavra feminismo só ter sido adotada a partir de 1937 (KONDER, 1998).

Parte das críticas de Fourier é voltada a posições que justificam e perpetuam o sofrimento humano como é o caso do cristianismo, do conservadorismo e do niilismo. Lehouck (1973, p.17) afirma:

\footnotetext{
Fourier encarna um momento único do pensamento ocidental; leva a crítica à religião, elaborada pelo movimento filosófico, até as últimas consequências lógicas, até o rechaço da moral da família e da hierarquia social e simboliza todo um momento em que a reação pós-revolucionária estava em todo seu apogeu, sustentando-se ainda por muito tempo boa parte das conquistas intelectuais do século XVIII, [...].
}

Desta forma, Fourier transcendia o economicismo de parte do pensamento socialista de sua época e de momentos posteriores. Não só criticava estruturas econômicas do capitalismo, mas, também, a moral inteira da sociedade contemporânea e seus costumes. Nesta perspectiva, a sociedade encontrava fundamento na hipocrisia ou em uma estrutura basicamente hipócrita, por se ter uma constante contradição entre palavras e ações, assim como, entre deveres e aspirações, uma vez que as pessoas aspiram à realização de seus desejos, no entanto, se reprimem e recorrem à moral para se auto-justificarem e reprimirem aos que os quiserem perseguir. O pensador francês antecipa propostas posteriores do socialismo libertário ao edificar comunas de associação voluntária como base do sistema político que substituiria o Estado e o capitalismo.

Com sua proposta, possuidora de um viés cooperativista, Fourier defendia que, caso se permitisse às pessoas realizar livremente suas inclinações ou "paixões", se produziria um estado de equilíbrio entre todos, ou, a "harmonia". Como fundamento da tese de Fourier estava a possibilidade de se estabelecer uma sociedade verdadeiramente justa, para a qual propôs a fundação de Falanstérios (Comunidades). Os benefícios obtidos seriam repartidos entre os membros da falange e os capitalistas que houvessem investido dinheiro na construção. Uma das cooperativas mais famosas, idealizada por Fourier, foi a Coopérative des bijoutiers em Doré (KONDER, 1998). Fourier pretendia convencer capitalistas a proporcionarem recursos necessários à construção de Falanstérios, mas, nenhum deles aceitou a proposta e Fourier morreu sem realizar seu ideal. 


\section{CONTEXTUALIZAÇÃO DA ECONOMIA SOLIDÁRIA}

Os primeiros focos de pensamento da Economia Solidária surgem no início do século XIX na Europa, com grande ênfase na França, sob o comando de Claude Saint-Simon (1760-1825), Charles Fourier (1772-1837), Pierre Proudhon (1865-1908) e Robert Owen (1773-1858). Estes elaboraram modelos sociais espetaculares de sociedade mutualista, cooperativista e solidária, porém não apresentaram uma formulação objetiva de como transformar tal sociedade e, em virtude disto, foram chamados por Karl Marx de socialistas utópicos. Apesar de não demonstrarem claramente os meios para se alcançar a sociedade por eles idealizada não se pode desmerecer seus pensamentos, uma vez que, foram estes os precursores e idealizadores de processos de articulação solidária.

Para entender melhor o porquê do aparecimento dos socialistas utópicos no início do século XIX é preciso lembrar o processo da Revolução Industrial na Europa como marco de fortalecimento e difusão do ideal liberal, o qual pautava-se no dogma da auto-regulação da economia. É através deste modelo ideológico que se inicia o processo de crises e misérias sistêmicas na condição de vida dos proletariados, entre elas se destacando o aumento crescente de desemprego que se alastrou pela Europa e por todo o resto do mundo.

Mediante todas as movimentações ideológicas, culturais, econômicas e sociais que estavam acontecendo na Europa e nos Estados Unidos do século XIX é que se observa o aparecimento de várias experiências solidárias influenciadas pela ideia da valorização do ser humano e do mutualismo através de cooperativas e associações de produção de socorro mútuo criadas por trabalhadores com o intuito de minimizar os efeitos trazidos pelo sistema liberal capitalista.

Um outro momento do ressurgimento do pensamento solidário se dá no início do século XX mediante a crise de superprodução (que ocorreu entre os anos de 1929 e 1932) responsável pela quebradeira na economia mundial ocasionando o aumento generalizado do desemprego e, é claro, demonstrando a deficiência do sistema capitalista liberalista.

A crise de 1929 é superada, principalmente, com a introdução de um novo pensamento teórico-econômico que se delineava no horizonte capitalista denominado de teoria Keynesiana. Esta propunha a intervenção do Estado na economia como forma de solução para os problemas capitalistas. Apesar desta teoria econômica, num primeiro momento, ter conseguido realizar seu objetivo (sanar a crise econômica e possibilitar crescimento do emprego e da economia), este quadro se reverte na segunda metade da década de 1970, quando se assiste ao surgimento de uma nova crise do sistema capitalista, que trás novamente o crescente fantasma do desemprego, o fechamento de empresas e o ressurgimento do ideal liberal (neoliberalismo). 
É nessa nova conjuntura econômica que, segundo Defourny (2001 apud LECHAT, 2002), reaparece em massa na Europa o processo cooperativista/associativista por parte das classes trabalhadoras de empresas autogeridas pelos próprios trabalhadores, cujo objetivo era o de lutar contra a exclusão social, assim como o de salvar e até mesmo criar empregos.

Ressalta-se que inúmeros movimentos sociais e étnicos surgiram nesse momento histórico e trouxeram como consequência uma nova visão do social a partir de sua relação com o econômico, com o político e com a relação do homem com o meio ecológico.

No Brasil, o movimento ganha forma na década de 1980 e impulsiona-se na metade dos anos 1990, resultante também da crise do emprego, nesse caso devido, além de outros fatores, à abertura do mercado interno às organizações estrangeiras (SINGER; SOUZA, 2003).

A literatura sobre o movimento cresce rapidamente a partir das primeiras publicações mencionando a denominação de Economia Solidária. Segundo Gaiger (2009), Luis Razeto foi o primeiro a introduzir o termo Economia Solidário na América Latina. E sua obra só chega ao Brasil em 1993, quando o autor a define como:

uma formulação teórica de nível científico, elaborada a partir e para dar conta de conjuntos significativos de experiências econômicas que compartilham alguns traços constitutivos e essenciais de solidariedade, mutualismo, cooperação e autogestão comunitária, que definem uma racionalidade especial, diferente de outras racionalidades econômicas (RAZETO, 1993, p.40).

Deste livro, outros foram publicados resultados de encontros e congressos sobre o assunto em diversas partes do Brasil. Vale ressaltar que muitos desses trabalhos foram decorrentes do que emergia na sociedade brasileira.

Das ações concretas que trabalharam com o conceito de Economia Solidária, primeiramente, destaca-se a ação das Cáritas, entidade ligada a CNBB (Conferência Nacional de Bispos do Brasil), no meio rural, financiando projetos de geração de trabalho e renda. Há também os empreendimentos que surgiram da falência de empresas, pela tomada da administração pelos trabalhadores, os quais passaram a ser os seus próprios patrões. Destaca-se a tomada da empresa calçadista Markeli, em São Paulo, e a Usina Catende, que desde 1995 continua sendo gerenciada pelos trabalhadores (SINGER, 2002).

Além dessas ações, como bem colocado por Singer (2002), vale apontar as Incubadoras Tecnológicas de Cooperativas Populares (ITCPs), instituições formadas por entidades universitárias, que dão suporte técnico, social e político a grupos sociais. A criação da Agência de Desenvolvimento Social, pela Central Única dos Trabalhadores (CUT) em parceria com a Unitrabalho e o Departamento Intersindical de Estatísticas e Estudos Sócio-Econômicos (DIEESE), vem fazendo também um trabalho importante de difusão do conhecimento sobre Economia Solidária entre os sindicatos e militantes do espaço social (SINGER, 2002). 
Em 2003, tem-se a criação da Secretaria Nacional de Economia Solidária (SENAES), no Governo do então Presidente Luís Inácio Lula da Silva, como a ação de maior importância para o movimento da Economia Solidária no Brasil. A SENAES, vinculada ao Ministério do Trabalho e Emprego, veio com a função de abarcar essa demanda de empreendimentos considerados econômicos solidários, principalmente os de baixa renda, "[...] visando à geração de trabalho e renda, à inclusão social e à promoção do desenvolvimento justo e solidário" (SENAES, 2009).

Uma das primeiras ações da Secretaria foi realizar um mapeamento de todos os possíveis e considerados empreendimentos econômicos solidários espalhados pelo Brasil. Dois já foram realizados (em 2005 e 2007) e outro está para ser iniciado no segundo semestre de 2009 ou em 2010. Aspectos como a infra-estrutura, as principais dificuldades de comercialização, a viabilidade, o acesso e a forma de financiamento, os apoios recebidos, a forma de gestão, entre outros foram levantados na pesquisa. Com essas informações foi criado o Sistema Nacional de Informações em Economia Solidária (SIES), um banco de dados que abrange todo o Brasil, facilitador de análise de bases local e nacional.

Outro fato relevante foi a elaboração da Carta de Valores, Princípios e Critérios para o Comércio Ético e Solidário do Brasil, entregue oficialmente ao Governo Federal do Brasil, nas mãos do Ministro do Desenvolvimento Agrário do Brasil, por representantes do Fórum de Articulação do Comércio Ético e Solidário (Faces) do Brasil, em junho de 2004.

Todas essas ações mostram como o movimento em pouco mais de duas décadas passou de ações pontuais resultantes do apelo à sobrevivência para alguns, para uma demanda em nível nacional, concretizada em ações dignificantes, que tem na autogestão e na solidariedade pilares para um crescimento político, sócio-ambiental e econômico.

\section{CONCEITUANDO ECONOMIA SOLIDÁRIA}

Em uma sociedade industrial centrada no mercado, a lógica da racionalidade instrumental, que amplia o controle da natureza, torna o desenvolvimento das forças produtoras a lógica da vida humana em geral. Mesmo a subjetividade caiu prisioneira da racionalidade instrumental. Segundo Guerreiro Ramos (1989, p.51): "homens e mulheres já não vivem mais em comunidade, onde um senso comum substantivo determina o curso de suas ações. Pertencem, em vez disso, a sociedades em que faz pouco mais além de responder a persuasões organizadas".

Além dessa ênfase na racionalidade instrumental, a ênfase na perda dos fundamentos e da transcendência, ou seja, o esfacelamento da religião, da ética, da moral e do sagrado, segundo Motta e Freitas (2000), são outras características das sociedades modernas. 
Guerreiro Ramos (1989) sustenta que a sociedade é constituída de uma variedade de enclaves, dos quais o mercado é apenas um. O homem, então, se empenha em tipos nitidamente diferentes, embora integrativos, de atividades substantivas. A partir dessa premissa o autor faz críticas à disciplina organizacional contemporânea que insiste em analisar as organizações somente por uma ótica utilitarista, como se o utilitarismo fosse o início e fim da vida em sociedade. Percebe-se, entretanto, que o movimento de revalorização das organizações se deve à "confirmação" do capitalismo como a "única" via capaz de promover o desenvolvimento econômico e à crescente legitimação da ideologia liberal em que o econômico assume papel predominante e subordina todas as demais esferas da vida social. Nestas condições, o termo "organização" é confundido com "organização econômica", e, o enclave econômico, o único passível de controle por organizações econômicas, é expandido para todos os outros setores sociais, chegando mesmo a ser tido como a sociedade em sua totalidade.

Dentro desse construto a Economia Solidária vem se solidificando como alternativa de desenvolvimento econômico aos modelos e padrões exploratórios da economia capitalista pelo qual nossa sociedade optou seguir. Ao mesmo tempo, está bastante claro que a Economia Solidária não atua em um campo fora do capitalismo e do mercado formal, mas, ao contrário, busca dentro da realidade existente alternativas de produção e de desenvolvimento econômico baseado em valores mais humanos, na busca da autonomia dos grupos que a praticam, em práticas sociais e ambientais sustentáveis. Também sob este vasto conceito encontram-se referências às ações cooperadas e associativas, com vistas e à busca da autogestão, atuação e inserção no mercado através de redes, relações de trabalho horizontais e equânimes.

Além disso, a dominação exercida pelo sistema capitalista de produção existe a tanto tempo que acabou gerando uma simplificação, típica do senso comum, ao considerar como atividades econômicas apenas aquelas que se inserem na chamada economia de mercado. Nessa concepção, Gaiger (2007) afirma que as empresas privadas capitalistas, ou empresas de mercado, aparecem exclusivamente como autênticas e legítimas agentes da economia, o que explica algumas denominações usuais como setor produtivo, referente às modernas e capitalizadas empresas de transformação, ou produtores rurais, que indiretamente tacham de improdutivos os pequenos proprietários e a produção familiar. $\mathrm{O}$ autor ainda sustenta que quem não pertence a esses setores modernos e competitivos é visto como atrasado ou é relegado a papel secundário. Para os pobres, uma espécie de economia de sobrevivência, com funções sociais, de freio à marginalização, mais que econômicas.

Esse tipo de caracterização pejorativa, referente ao grupo de produtores familiares, entretanto, não condiz com a grande importância econômica e social, principalmente em épocas de crise e recessão econômica. Atualmente, parte expressiva do PIB nacional, por exemplo, provém dessas atividades que, mesmo em segmentos mais pobres, não estão desprovidas de iniciativas e de estratégias econômicas, de considerável eficiência (GAIGER, 2007). 
Na verdade, outras economias produtivas e orientadas ao intercâmbio de bens existiam antes da disseminação das relações capitalistas de produção e de circulação de mercadorias. Dessa forma, o capitalismo é que representou a introdução do mercado como elemento preponderante da economia atual, gradativamente sobreposta a formas econômicas préexistentes, incorretamente classificadas como "pré-capitalistas", como se fossem um mero preâmbulo daquela e estivessem fadadas ao desaparecimento ou à condição de modo de produção marginal e subordinado. Contudo, conforme relatam Singer e Souza (2003), diante do advento das relações capitalistas os trabalhadores reagiram de várias formas, combatendo a exploração no interior da empresa capitalista, criando alternativas próprias de caráter associativo e cooperativo ou, acrescente-se, defendendo sistemas de vida autóctones, o patrimônio produtivo e saberes contra a ameaça de espoliação e de subordinação do capital. Essas reações se configuram, entre outras formas, na Economia Solidária.

À medida que esse movimento começa a ter êxito, estudiosos se propõem a estudar mais a fundo a sua viabilidade, não só nas cooperativas, mas também nas associações. Algumas concepções de Economia Solidária vão florescendo conforme os estudos vão se multiplicando e as características, seus fundamentos e princípios vão se formando, por isso tornar-se pertinente fazer considerações acerca do seu conceito por alguns renomados estudiosos que já têm certa experiência nos estudos sobre o assunto.

Ao considerar o ser humano na sua integralidade, como sujeito e finalidade econômica, a economia solidária desenvolve as capacidades dos trabalhadores e trabalhadoras, valoriza o associativismo comunitário, o cooperativismo, o trabalho familiar no sentido de buscar a inserção de atores excluídos ao convívio social. Trata-se de uma nova lógica de desenvolvimento sustentável com geração de trabalho e renda, mediante um crescimento econômico com proteção da natureza.

O antigo Secretário da SENAES, o Professor Paul Singer, foi um dos pioneiros na conceituação de Economia Solidária como sendo um modo de produção diferente dos que já existiram e com características próprias. O que pode diferenciar o seu entendimento dos outros autores é a perspectiva de tensão com o sistema vigente. Para Singer, a Economia Solidária pode ser um modo de produção que venha a substituir o modo de produção capitalista, assim como o socialismo e o comunismo. Em uma passagem, Singer e Souza (2003, p. 13) nos remetem a essa ideia: "A economia solidária surge como modo de produção e distribuição alternativo ao capitalismo, criado e recriado periodicamente pelos que se encontram (ou temem ficar) marginalizados do mercado de trabalho.". É possível observar o espírito revolucionário dos autores em sua citação.

Diferentemente de França-Filho e Laville (2004), que vêem na Economia Solidária um movimento que gesta a oportunidade de derrubar a ideia simplória e bem articulada (pelo sistema capitalista) de que só é possível a existência da economia de mercado no mundo. Ideia esta baseada no entendimento de Polanyi (2000), de que a economia mercantil, como hoje é 
concebida, é apenas uma forma de se enxergar a economia, havendo, portanto como citado anteriormente, a economia não-mercantil e a não-monetária. Isso é possível, pois no espaço da Economia Solidária existe a convivência de elementos de diferentes dimensões, como a "[...] venda de um produto ou prestação de um serviço (recurso mercantil); subsídios públicos oriundos do reconhecimento da natureza de utilidade social da ação organizacional (recurso nãomercantil); e trabalho voluntário (recurso não-monetário)." (FRANÇA-FILHO, 2002, p.13).

De acordo com a obra de Polanyi (2000), a primazia do econômico sobre o social é um fenômeno essencialmente moderno, isto é, em épocas mais remotas, o econômico era subjugado por atividades do tipo social. A existência de elementos como a reciprocidade, a redistribuição e a domesticidade, assim como o mercado, pautavam as relações interpessoais.

Guerreiro Ramos (1989) quando concebe o paradigma paraeconômico vai ao encontro do entendimento de Polanyi (2000) quando mostra que o mercado é apenas um das formas de organização existentes, e que a convivência entre os enclaves é inerente à sociedade.

Deste modo, França-Filho e Laville, em várias obras, conferem as organizações inseridas na Economia Solidária como sendo uma economia plural, onde seria possível se observar a presença dos elementos da economia mercantil, não-mercantil e não-monetária, além das dimensões econômica, social e política estarem em sintonia (LAVILLE; GAIGER, 2009, FRANÇAFILHO, 2009, 2008, 2003, 2002, FRANÇA-FILHO; LAVILLE, 2004, LAVILLE, 2002).

Além das particularidades expostas pelos autores, existem traços da Economia Solidária que são comuns na maioria dos discursos dos autores. Dentre as mais citadas estão a autonomia política, autogestão e solidariedade. A maioria deles concorda que a Economia Solidária nasce de uma organização autogestionada, onde a liberdade política, no sentido do seu membroparticipante ter voz na gestão do empreendimento, é possível. A tomada dos meios de produção pelos membros do empreendimento é outra característica importante, sem mencionar a solidariedade que é inerente à própria denominação do termo e significa o elemento mais ético e justo do movimento.

Sua prática, numa dimensão mais ampla, implica em sujeitos organizados a partir da base com vistas a romper a verticalidade absoluta das relações sociais, de trabalho e poder. A participação e a autonomia são vistas pelos pesquisadores como conquistas dos atores sociais, que rompem com os modelos e padrões de relações trabalhistas nas quais vivemos para, a partir daí, se desenvolverem econômica e socialmente. O trabalho assalariado/remunerado, como forma de produção de capital, é visto como forma de mediação social (OLIVEIRA apud GAIGER, 2004, p.323).

\section{INTERFACES DO PENSAMENTO DE FOURIER COM OS PRINCÍPIOS DA ECONOMIA SOLIDÁRIA}


Em atendimento ao objetivo principal deste trabalho, destaca-se como interfaces do pensamento de Fourier com os princípios da Economia Solidária: a defesa de melhores condições de trabalho e salário digno para os trabalhadores; a preocupação com a preservação do meio ambiente e com o desenvolvimento sustentável; o ideal de igualdade entre os gêneros; a defesa da necessidade de emancipação do indivíduo; a busca pelo prazer social através do consumo ético e consciente e de relações de transparência entre os que vendem e os que compram; e o acesso de todos à educação, independentemente de suas diferenças.

Fourier preconizava uma legislação de trabalho que garantisse aos trabalhadores remuneração com piso mínimo decente. Isso impulsionaria os trabalhadores à luta pela conquista de melhores remunerações e condições de trabalho. Em certo sentido, a ideia antecipava, com mais de um século de antecedência, aquilo que viria a ser a lei do salário mínimo. Além disso, percebe-se como este argumento fourierista está presente nos princípios da Economia Solidária. A própria história da Economia Solidária já é um relato claro da preocupação com o indivíduo e o coletivo quando as primeiras cooperativas são formadas. Como bem sugerem Cotera e Ortiz (2009, p. 60), a Economia Solidária é "um processo de desenvolvimento que procura beneficiar, sobretudo, os produtores excluídos ou empobrecidos possibilitando melhores condições econômicas, sociais, políticas, culturais, ambientais e éticas em todos os níveis desse processo [...]". Preocupação esta também assinalada pelo FACES (2004) quando lista princípios importantes que vão ao encontro da proposta fourierista, como: praticar níveis de remuneração e preço justo; valorizar a liberdade sindical e o reconhecimento efetivo do direito de negociação coletiva; valorizar a eliminação de todas as formas de trabalho forçado ou obrigatório; valorizar a erradicação da pobreza como um imperativo ético, social econômico e ambiental; e valorizar condições justas de produção e comercialização.

Fourier foi pioneiro na preocupação com a preservação do meio ambiente nas cidades modernas. Pode-se dizer que foi ele quem idealizou a ecologia. Propôs, entre outras medidas concretas, que fossem feitas leis capazes de enfrentar a expansão da especulação imobiliária, definidas normas para proteger áreas verdes e tomadas medidas práticas para impedir a construção de prédios que desrespeitassem os direitos dos cidadãos. Não apenas as cidades, mas também o campo era, para ele, motivo de preocupação. Advertiu a respeito da destruição das florestas pelos predadores industriais, bem como para a poluição das fontes de água potável. Esse ponto, em particular, está inserido na atuação das organizações de Economia Solidária como uma de suas premissas mais veementes, mediante políticas de apoio ao desenvolvimento local e sustentável e de proteção e restauração da integridade dos sistemas ecológicos da Terra, com especial preocupação pela diversidade biológica e por processos naturais que sustentem a vida, privilegiando-se a prevenção e a prudência diante dos limites do conhecimento humano. É pertinente ressaltar a compreensão de desenvolvimento de forma que, "o que importa é deixar bem claro que desenvolvimento não se confunde com crescimento econômico, que constitui condição necessária, porém não suficiente." (SACHS, 2005). 
Conforme Sachs (2005) o conceito de desenvolvimento sustentável exige que se pense de forma global, mas é preciso agir localmente. Neste sentido, a procura de um novo enfoque do desenvolvimento regional deve levar em conta não somente o aspecto econômico, mas também o político, social e ambiental, os quais são, também, necessários para o crescimento e manutenção de todos os agentes envolvidos (seres humanos, fauna, flora e a biodiversidade).

O Faces (2004) apresenta algumas ações da Economia Solidária voltadas ao meio ambiente: promoção de práticas de produção, comercialização e consumo que fortaleçam a justiça social, a preservação ambiental e a defesa da saúde humana; valorização do tratamento de todos os seres vivos com respeito e dignidade; e respeito ao meio ambiente.

Essas práticas são mais facilmente encontradas no meio rural, onde a cultura do consumo ou a patologia do consumismo é menos forte. Também, a relação do homem com o ambiente natural se dá de forma cotidiana, e as reações da natureza à intervenção humana são observáveis cotidianamente ou em um curto espaço de tempo.

Um terceiro argumento a ser considerado aponta para o papel pioneiro de Fourier no desencadeamento dos movimentos que têm denunciado, nestes dois últimos séculos, formas de discriminação das mulheres. Coelho (2009) defende a ideia de que a ciência econômica apesar de ser uma construção social omitiu a realidade específica das mulheres e, nessa medida, abordou as questões relacionadas à economia de forma truncada e imparcial.

Nenhum filósofo antes dele havia denunciado com tanta nitidez o sistema criado pela civilização para incutir nas mulheres um espírito de docilidade e obediência. Na perspectiva de Fourier de igualdade dos sexos, no plano dos direitos e das possibilidades concretas de afirmação pessoal, foi contemplada a reivindicação das diferenças a serem assumidas. Essa preocupação com as diferenças é nítida e constante em seu pensamento. Preservando o imprescindível espaço da afirmação da personalidade, segundo ele, seria impulsionado ao mesmo tempo o movimento pelo qual os indivíduos seriam levados voluntariamente a ultrapassar os limites da preocupação exclusiva de cada um consigo mesmo. Com isso, a ideia de Fourier pode, ainda hoje, estimular o aprofundamento de reflexões em torno da singularidade pessoal e da realização livre, ambas as dimensões necessárias aos valores comunitários.

O movimento da Economia Solidária prega liberdade de expressão e consciência autônoma perante o ambiente no qual os indivíduos estão inseridos, com isso preconceitos vão caindo por terra à medida que os princípios vão sendo introjetados, o que não é diferente ao sentimento de preconceito para com as mulheres. De acordo com o último mapeamento realizado pela SENAES, que se configurou no Relatório Nacional dos Empreendimentos de Economia Solidária no Brasil, 37\% dos indivíduos inseridos em empreendimentos econômicos solidários são mulheres (SENAES, 2007). Essa porcentagem mostra a inserção econômica e sóciopolítica que este movimento permite à grande maioria dessas mulheres que antes só realizavam atividades domésticas. Percebe-se, também, esses valores nos princípios propostos pelo Faces 
(2004): o respeito aos direitos das mulheres, crianças, grupos étnicos e trabalhadores (as); a promoção de uma cultura de tolerância, de não-violência e de paz; a franca liberdade de opinião e de expressão; o fortalecimento da democracia, respeito à liberdade de opinião e organização; e o reconhecimento das diferenças e a valorização das identidades, locais, rurais ou urbanas (FACES, 2004).

Da contribuição de Fourier à luta pelo fortalecimento de uma postura autoquestionadora por parte dos cientistas deriva uma importante colaboração à reflexão acerca da ideologia, adotando uma concepção negativa e caracterizando-a como uma distorção do conhecimento que se dá em sintonia com a divisão social civilizada e com as pressões promovidas por setores privilegiados poderosos. Para Konder (1998, p.70):

Em sua concepção de ideologia, então, Fourier não só se antecipou a Marx, como fez algumas observações que ainda têm o poder de chamar a nossa atenção para fenômenos ideológicos complexos e sutis, ligados aos sonhos, às aspirações, às fantasias e, sobretudo, aos desejos dos seres humanos.

Essa versão questionadora acerca da ideologia está associada, na Economia Solidária, ao fato desta funcionar como instrumento emancipador do indivíduo, servindo como garantia de que as atividades e instituições econômicas, em todos os níveis, promovam o desenvolvimento humano de forma equitativa e sustentável. Cattani (2009, p. 175) corrobora trazendo o conceito de emancipação social como sendo um "processo ideológico e histórico de libertação por parte das comunidades políticas ou de grupos sociais de dependência, tutela e dominação nas esferas econômicas, sociais e culturais".

Singer e Souza (2003) quando expõem sua opinião sobre o movimento econômico solidário mostra-o com um caráter questionador do sistema de produção capitalista e revolucionário, apresentando algumas diferenças quando comparada à concepção adotada por França-Filho e Laville (2004). No entanto, no discurso dos quatro autores apresentados percebese um ponto em comum, o caráter crítico do movimento diante da realidade.

Outra contribuição de Fourier encontra-se no tema do desejo, pois, segundo o autor francês, a exaltação do desejo não ocorria exatamente pela propaganda que, na civilização, acompanha e estimula o consumismo. O desejo, na perspectiva de Fourier, não estaria limitado aos prazeres, pois, estes, podem sofrer distorções causadas pelos mecanismos da civilização. Deformados, os indivíduos passam a atribuir importância maior aos prazeres obtidos na contenda de uns contra os outros do que aos prazeres partilhados. No Falanstério, os indivíduos não seriam pegos pelo imediatismo consumista. Essa concepção de prazer coletivo pode ser vista no espectro da Economia Solidária. Mais uma vez o Faces, em sua Carta de Valores, Princípios e Critérios para o Comércio Ético e Solidário do Brasil (FACES, 2004) apresenta algumas ações realizadas por empreendimentos econômicos solidários que defendem o consumo ético e consciente e relações de transparência entre os que vendem e os que compram, além de outras propostas como consideração da diversidade cultural; valorização do conhecimento e da 
identidade das comunidades tradicionais nas transações comerciais; integração entre produtor e consumidor para a construção coletiva do desenvolvimento sustentável; valorização de condições justas de produção e comercialização; e fornecimento de informação transparente ao consumidor. O mapeamento realizado pela SENAES (2007) confirma essas ações quando divulga que a grande maioria dos empreendimentos está envolvida com movimentos sociais e populares, realizam ações comunitárias e preocupam-se com o meio ambiente.

Por fim, o método educacional defendido por Fourier nos Falanstérios, que estabelecia o acesso à educação para todos, independentemente de suas diferenças, é coerente ao processo educacional defendido pela Economia Solidária (FACES, 2004): acesso universal à educação, ao cuidado da saúde e às oportunidades econômicas; e transmissão, por meio da educação formal e da aprendizagem ao longo da vida, dos conhecimentos, valores e habilidades necessários para um modo de vida sustentável.

\section{CONSIDERAÇÕES FINAIS}

Considerando que o objetivo do artigo foi evidenciar como o pensamento de Fourier está presente nos princípios da Economia Solidária, a leitura procedida foi centrada na ideologia deste filósofo e, por isso, não contemplou outros pensadores utópicos que igualmente contribuíram de maneira relevante para o construto do tema que hoje se configura como Economia Solidária. Assim sendo, é válido registrar o valor das contribuições de outros pensadores, contemporâneos de Fourier, como Robert Owen e Henry Saint-Simon.

A Economia Solidária é notadamente uma proposta de desenvolvimento solidário e includente. É uma configuração histórica da constante luta de trabalhadores (as) contra o desemprego e a exclusão social, não sendo apenas uma alternativa, mas, também, um viés questionador do status quo, se assemelhando ao caráter questionador da doutrina fourierista.

Apesar dos pensamentos de Fourier não terem sido colocados em prática, como o autor do Falanstério gostaria, e apesar de os mesmos não possuírem denotações científicas, por não se enquadrarem em um paradigma da ciência normal, as influências causadas por tais ideias no seu tempo e hoje, foram e continuam sendo significativas no momento em que se percebem retomadas a perspectivas de vida e de trabalho solidárias.

Muitas foram as críticas aos seus escritos, devido a alguns devaneios e elucubrações, o que não invalidam, os valores teóricos e práticos dos postulados por ele propostos. Nem o estigma de utópico, que o autor francês tanto rejeitava, invalida sua obra. Segundo Konder (1998), o que a utopia anula é o socialismo como política, é o movimento operário como movimento puramente político. O que traz modernidade ao fourierismo, por outro lado, é o seu apoliticismo ferrenho. $\mathrm{O}$ que haveria de mais fascinante no pensador francês seria o conjunto 
diversificado de ideias e a concomitante busca de integração numa totalidade. A razão para isso talvez resida, não apenas na crítica que faz ao capitalismo, mas, também, no fato de apresentar uma interpretação global e unitária do universo, sugerindo um plano de reorganização da sociedade através da associação voluntária que refletia aspirações de segmentos populacionais prejudicados pelo desenvolvimento capitalista.

Mais que nenhum outro pensador de seu tempo, Charles Fourier tentou resolver todos os problemas da sociedade através da elaboração de um complexo sistema de organização social no qual toda pessoa, atividade ou coisa ocupava antecipadamente um lugar bem determinado. Fourier partia da crença de que o ser humano é intrinsecamente bom, porque é o depositário de uma harmonia natural que reflete a própria harmonia do universo. O problema residia na sociedade existente, que impedia o desenvolvimento completamente livre das qualidades do ser humano.

Em síntese, conforme demonstrado no decorrer deste texto, existem várias características do pensamento de Fourier que embasam fortemente o construto Economia Solidária, o que demonstra a vitalidade de seus ideais na atualidade.

\section{REFERÊNCIAS}

1. CATTANI, A. D. Emancipação social. In: CATTANI, A. D.; LAVILLE, J. L.; GAIGER, L. I.; HESPANHA, P. Dicionário internacional da outra economia. São Paulo: Almedina, 2009.

2. COELHO, L. Economia feminista. In: CATTANI, A. D.; LAVILLE, J. L.; GAIGER, L. I.; HESPANHA, P. Dicionário internacional da outra economia. São Paulo: Almedina, 2009.

3. COTERA, A.; ORTIZ, H. Comércio justo. In: CATTANI, A. D.; LAVILLE, J. L.; GAIGER, L. I.; HESPANHA, P. Dicionário internacional da outra economia. São Paulo: Almedina, 2009.

4. ENGELS, F. Do socialismo utópico ao socialismo científico. São Paulo: Global Editora, 1981.

5. FACES DO BRASIL. Carta de valores, princípios e critérios para o Comércio Ético e Solidário do Brasil, 2004.

6. FRANÇA FILHO, G. C. Incubação de redes de economia solidaria. In: CATTANI, A. D.; LAVILLE, J. L.; GAIGER, L. I.; HESPANHA, P. Dicionário internacional da outra economia. São Paulo: Almedina, 2009.

7.

A via - sustentável solidária no desenvolvimento local. Organizações \& Sociedade, Salvador, v.15, n. 45, abr/jun, 2008.

8. A temática da economia solidária e suas implicações originais para o campo dos estudos organizacionais. RAP, Rio de Janeiro, v. 37, p.11-31, Jan./Fev, 2003.

9. Terceiro setor, economia social, economia solidária e economia popular: traçando fronteiras Conceituais. Bahia Análise \& Dados, Salvador, v.12, n.1, p.9-20, jun/2002.

10. FRANÇA-FILHO, G. C.; LAVILLE, J. L. Economia Solidária: uma abordagem internacional. Porto Alegre: Editora da UFRGS, 2004. 
11. GAIGER, L. I. Empreendimento econômico solidário. In: CATTANI, A. D.; LAVILLE, J. L.; GAIGER, L. I.; HESPANHA, P. Dicionário internacional da outra economia. São Paulo: Almedina, 2009.

12. A Economia Solidária no Brasil: refletindo sobre os dados do primeiro Mapeamento Nacional. In: II Seminário Nacional do Núcleo de Pesquisa sobre Movimentos Sociais. Santa Catarina, UFSC. Anais... abr. 2007. Disponível em: <http://www.ecosol.org.br/txt/mapeamento1.pdf>. Acesso em: 10/11/2008.

13. . (Org.). Sentidos e experiências da Economia Solidária no Brasil. Porto Alegre: Editora da UFRGS, 2004.

14. GUERREIRO RAMOS, A. A nova ciência das organizações: uma reconceituação da riqueza das nações. 2 ed. Rio de Janeiro: FGV, 1989.

15. KONDER, L. Fourier, o socialismo do prazer. Rio de Janeiro: Civilização Brasileira, 1998.

16. LAVILLE, J. L. Fato associativo e Economia Solidária. Bahia Análise e Dados, Salvador, Superintendência de Estudos Econômicos e Sociais da Bahia, v. 12, n. 1, p. 25-34, jun. 2002.

17. LAVILLE, J. L.; GAIGER, L. I. Economia Solidária. In: CATTANI, A. D.; LAVILLE, J. L.; GAIGER, L. I.; HESPANHA. Dicionário Internacional da outra economia. São Paulo: Almedina, 2009.

18. LECHAT, N. M. P. As raízes históricas da economia solidária e seu aparecimento no Brasil. Campinas, $2002 . \quad$ Disponível em: <http://www.cultura.ufpa.br/itcpes/documentos/ecosolv1.pdf\#page=4>. Acesso em: 19/01/2009.

19. LEHOUCK, E. Fourier o la armonia y el caos. Barcelona: Labor, 1973.

20. MOTTA, F.; FREITAS, M. Vida Psíquica e Organização. São Paulo: FGV, 2000.

21. POLANYI, K. A grande transformação: as origens da nossa época. 2. ed. Rio de Janeiro: Elsevier, 2000.

22. RAZETO, L. Economia de solidariedade e organização popular. In: GADOTTI, M.; GUTIÉRREZ, F. (org.). Educação comunitária e economia popular. São Paulo: Cortez, 1993.

23. SACHS, I. Prefácio. In: VEIGA, J. E. Desenvolvimento Sustentável, o desafio do século XXI. Rio de Janeiro: Editora Garamond, 2005.

24. SENAES. Relatório Nacional dos empreendimentos de Economia Solidária no Brasil. 2007. Disponivel em: <http://www.mte.gov.br>. Acesso em: 08 jul. 2008.

25. Objetivos. Brasília, 2009. Disponível em: <http://www.mte.gov.br/ecosolidaria/secretaria_nacional.asp>. Acesso em: 20 jun. 2009.

26. SINGER, P.; SOUZA, A. R. A economia solidária no Brasil: a autogestão como resposta ao desemprego. 2. ed. São Paulo: Contexto, 2003.

27. SINGER, P. Introdução à Economia Solidária. São Paulo: Editora Fundação Perseu Abramo, 2002.

28. VEIGA, J. E. Desenvolvimento Sustentável, o desafio do século XXI. Rio de Janeiro: Editora Garamond, 2005. 